\title{
Inter-group violence among early Holocene hunter-gatherers of West Turkana, Kenya
}

Mirazón Lahr, M..$^{1,2^{*}}$; Rivera, F. ${ }^{1 \S}$; Power, R.K. ${ }^{1 \S}$; Mounier, A. ${ }^{1}$; Copsey, B. ${ }^{1}$; Crivellaro, F. ${ }^{1}$; Edung, J.E. ${ }^{3}$; Maillo Fernandez, J.M. ${ }^{4} ;$ Kiarie, C. ${ }^{2}$; Lawrence, J. ${ }^{1}$ Leakey, A. ${ }^{2}$; Mbua, E. ${ }^{5}$; Miller, H. ${ }^{1}$; Muigai, A. ${ }^{6}$; Mukhongo, D.M. ${ }^{1}$; Van Baelen, A. ${ }^{1}$; Wood, R. ${ }^{7}$; Schwenninger, J.L. ${ }^{8}$; Grün, R. ${ }^{7,9}$; Achyuthan, H. ${ }^{10}$; Wilshaw, A. ${ }^{1}$; \& Foley, R.A. ${ }^{1,2}$

${ }^{1}$ Leverhulme Centre for Human Evolutionary Studies, Department of Archaeology \& Anthropology, University of Cambridge, Fitzwilliam Street, Cambridge, CB2 1QH, UK

${ }^{2}$ Turkana Basin Institute, Nairobi, Kenya

${ }^{3}$ National Museums of Kenya, Jomo Kenyatta House, P.O. Box 152-30500, Lodwar, Kenya

${ }^{4}$ Departamento de Prehistoria y Arqueologia, UNED, c/ Paseo Senda del Rey, 7, 28040

Madrid, Spain

${ }^{5}$ National Museums of Kenya, P.O. Box 40658-00100, Nairobi, Kenya

${ }^{6}$ Jomo Kenyatta University of Agriculture and Technology, P.O. Box 62000-00200, Nairobi, Kenya

${ }^{7}$ Research School of Earth Sciences, The Australian National University, Building 142, Mills Road, Acton ACT 2601, Australia

${ }^{8}$ Research Laboratory for Archaeology and the History of Art, University of Oxford, Dyson Perrins Building, South Parks Road, OX1 3QY, UK

${ }^{9}$ Research Centre for Human Evolution, Environmental Futures Research Institute, Griffith University, 170 Kessels Road, Nathan, QLD 4111, Australia

${ }^{10}$ Department of Geology, Anna University, Chennai, Tamil Nadu 600025, India

* corresponding author

$\S$ these authors contributed equally to the work 
The nature of inter-group relations among prehistoric hunter-gatherers remains disputed, with arguments in favour and against the existence of warfare before the development of sedentary societies ${ }^{1,2}$. Here we report on a case of inter-group violence towards a group of hunter-gatherers from Nataruk, west of Lake Turkana, which in the late Pleistocene/early Holocene extended c. $30 \mathrm{~km}$ beyond its present-day shore ${ }^{3}$. Ten of the twelve articulated skeletons found at Nataruk show evidence of having died violently at the edge of a lagoon, into which some of the bodies fell. The remains from Nataruk are unique, preserved by the particular conditions of the lagoon with no evidence of deliberate burial. They offer a rare glimpse into the life and death of past foraging people, and evidence that warfare was part of the repertoire of inter-group relations among some prehistoric hunter-gatherers.

The origins of war are controversial. Although it is clear that inter-group violence, including intentional lethal attacks on individuals, is part of the behavioural repertoire of chimpanzees $^{4,5}$, evolutionary explanations for human violence have been disputed ${ }^{1,2}$. This uncertainty arises because evidence that informs on the nature of relationships among groups in the past is scarce, and most models of prehistoric inter-group relations rely on ethnographic information from small-scale societies. This information is very variable, partly because of differences in the definition of war, partly because the circumstances of modern hunter-gatherers are not analogous to the past, and partly because of the inclusion of data on both intra- and inter-societal warfare ${ }^{1,2,6-8}$. After numerous analyses of the scarce ethnographic data, researchers remain deeply divided as to whether antagonistic relations formed a significant element of social life in prehistory ${ }^{2,6,7,9-18}$. Antagonistic relations can be described as acts of aggression towards an individual or a small foraging/scouting party, or as warfare. Prehistoric cases of the former are difficult to differentiate from inter-personal 
violence $^{6}$, the most frequent form of lethal aggression among recent foragers ${ }^{2}$; cases of largescale violent encounters of two groups are relatively common among settled societies ${ }^{6,19}$. It is evidence for inter-group violence among prehistoric hunter-gatherers, however, that is extremely rare. The Qadan graveyard at Jebel Sahaba, Sudan, where 23 of 58 bodies show evidence of violence ${ }^{20}$, stands as the best example. Although undated, the Jebel Sahaba remains were estimated to have a late Pleistocene age (often quoted as 14,000-12,000 years) on the basis of the character of the lithic industry ${ }^{20}$. The Jebel Sahaba individuals were buried, individually or in small groups, presumably by their own community, after the raids or feuds during which they died. The existence of such cemetery space suggests a level of sedentism that would align the Jebel Sahaba violent deaths to later examples. In contrast, the human remains from the site of Nataruk record the intentional killing of a small band of foragers, and thus unique evidence of a warfare event among hunter-gatherers in prehistory.

Nataruk is located near the reconstructed margin of the late Pleistocene/early Holocene lake PalaeoTurkana, at the eastern edge of a small depression that would have formed a lagoon during periods of high precipitation (Extended Data Fig. 1a). In 2012, the remains of a minimum of 27 individuals were discovered partially or completely exposed on the surface of a gravel bar ridge that runs parallel to the dunes for $\sim 200 \mathrm{~m}$ ENE-WSW, rising $\sim 1 \mathrm{~m}$ above the rest of the plain, and on two mounds $\sim 70 \mathrm{~m}$ to the northeast (Fig. 1, Extended Data Fig. 1b, Extended Data Fig 2, Supplementary Information 1). Small to medium-sized gravel covers the surface of the ridge and mounds, lying loosely over a layer of lake sediments. The carbonates, nodules and shells of gastropods and clams, suggest the area was once partly covered by the small lagoon. The majority of the fragmentary animal remains recovered are aquatic/lake-edge animals (Supplementary Information 4). The site of Nataruk has relatively few archaeological remains. The excavation of 12 skeletons in situ yielded only 131 lithics; 
however, an area of approximately $6 \times 6 \mathrm{~m}$ at the top of the ridge, overlying some of the skeletal remains, had a localised concentration of 628 lithics, and may reflect an ephemeral later occupation of the site (Supplementary Information 5). The lithic industry is similar to other Later Stone Age (LSA) assemblages in the area ${ }^{21-23}$, including fragments of barbed bone harpoons typical of early Holocene hunter-fishers of Turkana ${ }^{24,25}$.

The human skeletal remains had no collagen. Two radiocarbon dates were obtained from sediment samples collected from sub-surface sediments above the skeletons, four from shells found next to or in direct association with the human remains, and another one from within an Optically-Stimulated-Luminescence (OSL) dating sample collected from the lake sediments in which one of the skeletons was found. As expected, the surface sediments above the skeletons are younger $(7,270-8,160$ cal BP) than the lagoon's shells $(9,030-11,750$ cal BP; Extended Data Table 1, Extended Data Fig. 3a), and correspond to a later period of high lakelevels in the area $^{26}$. An OSL age of 9,680 $\pm 805 \mathrm{yrs}$ obtained from the lake sediments adjacent to one of the skeletons is similar to those of the lagoon shells. Lastly, the majority of fifteen U-series minimum dates obtained from the skeletons also fall into an age range of early to mid-Holocene, although some results extend back to c. 40,000 years ago. Some of these older ages may have been affected by U leaching (Extended Data Fig. 3b,c). Although a mid-Upper Pleistocene age for the remains cannot be fully excluded, an age estimate of $\sim 9,500-10,500$ years BP for the people of Nataruk is consistent with dates on shells, harpoons and charcoal from sites in the immediate vicinity, and corresponds to a phase of early Holocene high lake-levels in Turkana ${ }^{3}$ (Extended Data Table 2, Supplementary Information $6)$. 
Most of the remains of the people who died at Nataruk were found fully exposed and fragmented, surviving in varying states of preservation and erosion; twelve individuals were partially preserved articulated in situ. Among these, no burial pit was identified, and no standardised orientation or position of head, face or body was observed (Fig. 2). The total number of individuals who died at the site is unknown, as only those partially exposed were excavated. Of the 27 individuals recorded, 21 were adults ( 8 males, 8 females, and 5 unknown) (Supplementary Information 2). Partial remains of 6 children were found comingled or in close proximity to the remains of 4 adult women and of 2 fragmentary adults of unknown sex. The remains of a 6-9 month-old foetus were recovered from within the abdominal cavity of one of the adult females, representing a $28^{\text {th }}$ individual. No children were found with or near any of the men. All except one of the juvenile remains are children under the age of 6 ; the exception is a teenager, aged $12-15$ years dentally, but whose bones are noticeably small for their age.

Ten of the twelve skeletons in situ show evidence of major traumatic lesions that would have been lethal in the immediate to short-term (Table 1, Extended Data Figs. 4-7, Supplementary Information 3, Supplementary Figure 1). These include five, possibly six, cases of sharpforce trauma to the head and/or neck likely associated with arrow wounds, five cases of blunt-force trauma to the head, two cases of possible ante-mortem depressed bilateral fractures of the knees, two cases of multiple fractures to the right hand, and a case of fractured ribs. Only two of the skeletons in situ show no apparent evidence of peri-mortem trauma, although in both cases, the position of the hands suggests the individuals may have been bound at the time of death. In all of the cases of cranial trauma, the compression of bones is localised and cannot be explained by taphonomic forces, as unaffected cranial elements retain the original size and shape around the fractured portions. Three artefacts were 
found within or embedded in two of the bodies (Fig. 3). The first of these is an obsidian bladelet found embedded in one of the male crania; the others are two microliths, a chert lunate and an obsidian trapeze, found inside the pelvic and thoracic cavities of a male skeleton; all three show impact scars. Interestingly, an obsidian lithic was also found embedded in the foot bones of a skeleton at the site of Lothagam ${ }^{27}$. The fact that obsidian is relatively rare in other early Holocene LSA sites of southwest Turkana may suggest that the two groups confronted at Nataruk had different home ranges. The presence of projectile points embedded in the skeletal remains or within the body cavity is considered diagnostic of inter-group conflict, while fractures resulting from blunt and sharp force trauma, particularly to the head, neck, ribs and hands, are indicative of deliberate violent trauma ${ }^{28,29}$. A third diagnostic feature of warfare in the past, the presence of cut-marks associated with dismembering and trophy-taking (such as scalping) ${ }^{29}$ is not observed at Nataruk.

As one of the clearest cases of inter-group violence among prehistoric hunter-gatherers, the event recorded at Nataruk offers information on the socio-economic conditions that marked the presence of warfare. However, there are two interpretations of how this fact impinges on our understanding of war among foraging societies. West Turkana 10,000 years ago was a fertile lakeshore landscape sustaining a substantial population of hunter-gatherers; the presence of pottery may be indicative of some storage and so reduced mobility. Thus, the massacre at Nataruk could be seen as resulting from a raid for resources - territory, women, children, food stored in pots - whose value was similar to those of later food-producing societies among whom violent attacks on settlements and organised defence strategies became part of life. In this light, the importance of what happened at Nataruk would be in terms of extending the chronology and degree of the same underlying socio-economic conditions that characterise early warfare in more recent periods. Alternatively, Nataruk may 
offer evidence not of changing conditions towards a settled, materially richer and demographically denser way of life, but of a standard antagonistic response to an encounter between two social groups. As such, Nataruk would be important for the particular circumstances that preserved an ephemeral, but perhaps not unusual event in the life of prehistoric foraging societies. In either case, the deaths at Nataruk are testimony to the antiquity of inter-group violence and war.

\section{References}

1. Wrangham, R. \& Glowacki, L. Intergroup aggression in chimpanzees and war in nomadic hunter-gatherers. Human Nature 23, 5-29 (2012).

2. Fry, D. P. \& Soderberg, P. Lethal aggression in mobile forager bands and implications for the origins of war. Science 341, 270 (2013).

3. Garcin, Y. et al. Late Pleistocene-Holocene rise and collapse of Lake Suguta, northern Kenya Rift. Quaternary Science Reviews 28, 911-925 (2009).

4. Wilson, M. L. \& Wrangham, R. W. Intergroup relations in chimpanzees. Annual Review of Anthropology 32, 363-392 (2003).

5. Wilson, M. L. et al. Lethal aggression in Pan is better explained by adaptive strategies than human impacts. Nature 513, 414-417 (2014).

6. Bowles, S. Did Warfare Among Ancestral Hunter-Gatherers Affect the Evolution of Human Social Behaviors? Science 324, 1293-1298 (2009).

7. Kelly, R. C. The evolution of lethal intergroup violence. PNAS 102, 15294-15298 (2005).

8. Thorpe, I.J.N. in Warfare, Violence and Slavery in Prehistory, Oxford (Thorpe, I.J.N) 1-18 (BAR International Series, 1374, 2005).

9. Burch, E. S. Alliance and Conflict: The world system of the Inupiaq Eskimos. (University of Nebraska Press, 2005).

10. Ember, C. R. Myths about hunter-gatherers. Ethnology 17, 439-448 (1978).

11. Fry, D. P. Beyond war: The human potential for peace. (Westview Press, 2007).

12. Goldschmidt, W. in The Social Dynamics of Peace and Conflict (Rubenstein, R. A. \& Foster, M. L.) 47-65 (Westview Press, 1988).

13. Hobhouse, L. T., Wheeler, G. C. \& Ginsberg, M. The material culture and social institutions of the simpler people. (Chapman \& Hall, 1915).

14. Leavitt, G. C. The frequency of warfare: an evolutionary perspective. Sociology Inquiry 47, 49-58 (1977).

15. Otterbein, K. F. How war began. (Texas A\&M University Press, 2004).

16. Radcliffe-Brown, A. R. The Andaman Islanders: A Study in Social Anthropology. (Cambridge University Press, 1922).

17. Schapera, I. The Khoisan peoples of South Africa. (Routledge and Kegan Paul, 1930).

18. Wright, Q. A Study of War. (University of Chicago Press, 1942).

19. Keely, L. H. War before Civilization. (Oxford University Press, 1996).

20. Wendorf, F. in The Prehistory of Nubia (Wendorf, F.) 2, 954-1040 (Southern 
Methodist University Press, 1968).

21. Robbins, L. H. The Lothagam Site. (Michigan State University, 1974).

22. Robbins, L. H. Lake Turkana archaeology: The holocene. Ethnohistory 53, 71-93 (2006).

23. Beyin, A. Recent archaeological survey and excavation around the Greater Kalakol area, West Side of Lake Turkana: Preliminary Findings. Nyame Akuma 75, 40-50 (2011).

24. Robbins, L. H. Bone artefacts from the Lake Rudolf Basin, East Africa. Current Anthropology 16, 632-633 (1975).

25. Barthelme, J. W. Fisher-Hunters and Neolithic Pastoralists in East Turkana, Kenya. (British Archaeological Reports International Series, 1985).

26. Forman, S. L., Wright, D. K. \& Bloszies, C. Variations in water level for Lake Turkana in the past 8500 years near Mt. Porr, Kenya and the transition from the African Humid Period to Holocene aridity. Quaternary Science Reviews (2014).

27. Angel, J. L., Phenice, T. W., Robbins, L. H. \& Lynch, M. M. Late Stone Age fishermen of Lothagam, Kenya. 3, (Michigan State University, 1980).

28. Sauer, N. J. in Forensic Osteology (Reichs, K. J.) 321-332 (Charles C Thomas Publisher, 1998).

29. Smith, M. O. Beyond palisades: The nature and frequency of late prehistoric deliberate violent trauma in the Chickamauga Reservoir of East Tennessee. American Journal of Physical Anthropology 121, 303-318 (2003).

Supplementary Information is linked to the online version of the paper at www.nature.com/nature.

\section{Acknowledgements}

We thank the Office of the President of Kenya, the Turkana Province government, and the National Museums of Kenya for permission to conduct research (NCST/5/002/R/419), the Turkana people of Locher Akwan, Lokwar Ankhaleso, Lotukumo, Eporon, and Natome for permission to work in their area and assistance, the Turkana Basin Institute for logistical and laboratory support, the British Institute in Eastern Africa, Prof. R Leakey, Prof. M Leakey and Prof. L Martin for support and advice, and the 2012 IN-AFRICA field team (E Murungi, J. Oltimbao, J. Lokuruka, D. Lomuria, Musa, J. Ekeno, J. Erupe, J. Lopua, R. Ng'irotin, P. Amuk, P. Atadeit, M. Emusugut, F. Lowan, R. Ng'ichila, S. Eperon, P. Eperon, T. Echulum), specially Pedro Ebeya who found the site. We thank Prof. S. Black and Dr C. Cunningham 
for advice on the foetal remains, Beta Analytic for advice and assistance, and F. Lahr for assistance with imaging and illustrations. Funding was provided by a European Research Council Advanced Award to M.M.L. (IN-AFRICA, ERC 295907; http://in-africa.org), the Newby Trust, and the McDonald Institute for Archaeological Research, University of Cambridge.

\section{Author Contributions}

M.M.L. directed the study and fieldwork; M.M.L., F.R., A.M., A.W., J.E.E., J.L., H.M., D.M.M., A.Mu., B.C., H.A. and R.A.F. participated in the fieldwork and excavations; M.M.L., F.R., J.E.E., J.L., H.M. and D.M.M. excavated the Nataruk skeletons; M.M.L., F.R., R.K.P., A.W., A.L. and K.C. cleaned, prepared and reconstructed the fossils at the Turkana Basin Institute (TBI) research laboratories; M.M.L. and R.K.P. analysed and described the lesions and pathologies; M.M.L. prepared the illustrations of Figure 2 and illustration and photographs of Extended Figs. 4-7; A.W. prepared the archaeological illustrations and samples for radiocarbon dating; A.M. prepared the 3D model of KNM-WT 71264 in Extended Figure 8; M.M.L., A.W., F.R. and F.C. carried out the fauna identification; A.W. and J.M.M.F. analysed the lithics following protocols developed by R.A.F., and A.W. wrote the archaeology section of the SI; A.V.B. prepared the GIS maps; H.A., R.A.F., M.M.L. and A.M. carried out the geomorphological study; R.W. did radiocarbon dating; J.-L.S. did the OSL date; R.G. examined all materials at TBI for dating, and did the U-series dates; M.M.L. wrote the paper, with contributions from R.A.F., R.G., R.K.P., A.W., E.M., R.W., J.-L.S..

Author Information. The human remains from the site of Nataruk are curated for the National Museums of Kenya (KNM-WT 71251-71277) at the Turkwel Station of the Turkana Basin Institute, Kenya. Reprints and permission information is available at 
www.nature.com/reprints. The authors declare no competing financial interests. Correspondence and requests for materials should be addressed to M.M.L. (mbml1@cam.ac.uk) and R.A.F. (af10@,cam.ac.uk). 
Table 1 - Distribution of observable trauma among the articulated human skeletons from Nataruk with more than $20 \%$ of the post-cranial skeleton preserved.

\begin{tabular}{|c|c|c|c|c|}
\hline Individual & Sex & Age & Trauma and other relevant features & $\begin{array}{c}\text { Position of } \\
\text { lesion(s) and } \\
\text { other features }\end{array}$ \\
\hline WT 71251 & $\sigma^{\prime}$ & Adult & $\begin{array}{l}\text { - } \text { projectile embedded in cranium } \\
\text { - } \text { perforating lesion on right parietal bone } \\
\text { - } \quad \text { possible knee depressed fractures }\end{array}$ & $\begin{array}{l}\text { - Head } \\
\text { - Head } \\
\text { - Knee }\end{array}$ \\
\hline WT 71253 & $\sigma^{\prime \prime}$ & Adult & $\begin{array}{l}\text { - blunt force trauma on left temporal bone } \\
\text { - perforating lesions on vertebrae }\end{array}$ & $\begin{array}{l}\text { - Head } \\
\text { - } \quad \text { Neck (x2) }\end{array}$ \\
\hline WT 71254 & Q ? ? & Adult & $\begin{array}{l}\text { - perforating lesion on frontal bone } \\
\text { - sharp force trauma on mandible } \\
\text { - hand fractures }\end{array}$ & $\begin{array}{l}\text { - Head } \\
\text { - Head } \\
\text { - Hand }\end{array}$ \\
\hline WT 71255 & Q & Adult & $\begin{array}{l}\text { - bound? } \\
\text { - } \text { pregnant or recently delivered (foetus/newborn) }\end{array}$ & - Hands \\
\hline WT 71256 & Q & Adult & $\begin{array}{l}\text { - perforating lesion on vertebrae } \\
\text { - hand fracture }\end{array}$ & $\begin{array}{l}\text { - Neck } \\
\text { - Hand }\end{array}$ \\
\hline WT 71257 & $\sigma^{\prime \prime}$ & Adult & - blunt force trauma on left temporal bone & - Head \\
\hline WT 71258 & O & Adult & $\begin{array}{l}\text { - projectiles within body cavity } \\
\text { - bound? }\end{array}$ & $\begin{array}{l}\text { - Thorax } \\
\text { - Hands }\end{array}$ \\
\hline WT 71259 & Q & Adult & $\begin{array}{l}\text { - } \text { consecutive rib fractures } \\
\text { - possible knee depressed fractures } \\
\text { - unnatural position of left foot } \\
\text { - bound? }\end{array}$ & $\begin{array}{l}\text { - Ribs } \\
\text { - Knee } \\
\text { - Foot } \\
\text { - Hands }\end{array}$ \\
\hline WT 71260 & $\sigma^{\prime \prime}$ & Adult & - bound? & - Hands \\
\hline WT 71263 & ర" & Adult & - sharp force trauma on frontal bone & - Head \\
\hline WT 71264 & $\sigma^{\pi}$ & Adult & - blunt force trauma on left temporal bone & - Head \\
\hline WT 71265 & Q & Adult & - blunt force trauma on frontal bone & - Head \\
\hline
\end{tabular}

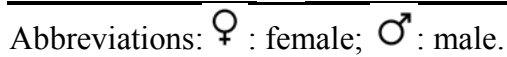




\section{Figure Captions}

Figure 1 - Spatial distribution of the human skeletons discovered at the site of Nataruk.

a. distribution of the remains of 27 individuals were found along a sandy ridge and on a small mound at Nataruk; 15 exposed and fragmentary (black), and twelve articulated skeletons (red). b, c. Distribution of the skeletons found on the mound and sandy ridge, respectively, with inset photographs of the position and direction of the articulated human remains. Background image: ArcGIS Online Basemap - World Imagery (Source: Esri, DigitalGlobe, GeoEye, i-cubed, USDA, USGS, AEX, Getmapping, Aerogrid, IGN, IGP, swisstopo, and the GIS User Community).

Figure 2 - Schematic drawings illustrating the position of the twelve articulated skeletons from Nataruk; details of lesions are shown in Extended Data Figs. 4-7 and Supplementary Figure 1, and described in Supplementary Information 3.3.

Figure 3 - Lithics found in direct association with human remains at Nataruk. a. KNMWT 71251 cranium as found in situ, with obsidian bladelet found embedded in the left parietal bone. b. Detail of obsidian bladelet, showing impact scar at the tip. c. and d. Microliths found within the body of KNM-WT 71258, an obsidian crescent, with broken tip, found inside the pelvic basin, and a chert microlith, also with a broken tip, found inside the thoracic cavity. Scale bar units represent $1 \mathrm{~cm}$. 


\section{Methods}

Core osteological assessment of the skeletal remains from Nataruk. Age at death of juvenile remains was assessed through dental development and epiphyseal fusion ${ }^{30-32}$. Adult remains were identified cranially by presence of the third molar in occlusion and/or fusion of the spheno-occipital synchondrosis, and post-cranially by the fusion of epiphyses and $\operatorname{size}^{33,34: 21-38}$. Adults were further grouped into young, middle-aged and old adults depending on degree of dental wear, cranial suture obliteration, presence of degenerative joint disease, and other age-related osteological changes (including pubic symphyses, auricular surfaces and sternal rib-end morphology $)^{35-38}$. Sex was determined from pelvic and cranial features following standard practice ${ }^{34: 16-20}$. More details in Supplementary Information 2.

Identification of peri-mortem trauma in the skeletal remains from Nataruk. Following standard practice $28,29,39-43$, the presence of projectile points embedded in the bone or within the body cavity, and peri-mortem fractures resulting from blunt or sharp-force trauma were considered evidence of violence. Ante-mortem vs peri-mortem trauma was diagnosed on the basis of: (a) evidence of healing and/or periosteal reaction ${ }^{28,44}$, and (b) the context of the skeletons and distribution of lesions, noting that violent injuries are most often observed in ribs, scapulae, forearms, hands, and particularly in the head and neck ${ }^{45-48}$, and that blunt-force peri-mortem traumatic lesions in the head can be considered diagnostic of inter-group conflict in some contexts (for example ${ }^{29,49-51}$ ). Peri-mortem fractures were identified by: (1) presence of depressed adhering bone fragments, (2) secondary linear and/or concentric radiating fractures, (3) inner bevelling of the margins of the lesion, (4) irregular, sharp or splintered edges (instead of shattered), (5) flaking of the internal fracture surface, and (6) absence of discoloration (i.e. the colour of the borders of the lesion is consistent with the surrounding bone $)^{28,49,52-62}$. Perforating lesions were identified by: (a) a linear, circular or ellipsoidal section; (b) well-defined edges and either smooth or serrated/splintered margins, which may 
be polished; (c) a V, semi-V or U shaped cross-section; (d) the presence of internal bevelling and/or parallel striations; and (e) anatomical position consistent with a projectile's trajectory. Perforating lesions caused by non-sharp projectiles, such as a bone point or polished arrow shaft, were identified by typically rounded or oval margins, with rounded edges ${ }^{63}$. Further information on the traumatic lesions observed in Nataruk in Supplementary Information 3.

Radiocarbon Dating. Two sediment samples from above two of the skeletons were dated by Beta Analytic Inc.. These were sieved to $<180 \mu \mathrm{m}$, and the resulting bulk organic fraction acid-washed to remove carbonates in a series of $1.0 \mathrm{~N} \mathrm{HCl}$ leaches at $90^{\circ} \mathrm{C}$ for $\geq 1.5 \mathrm{hr}$, followed by serial rinses in de-ionized water at $70^{\circ} \mathrm{C}$, drying in an oven at $90^{\circ} \mathrm{C}$ for $12-24 \mathrm{hrs}$, and further homogenization and $\mathrm{HCl}$ sub-sample application to validate the absence of carbonates. Microscopic examination of the entire remaining sample insured removal of any root hairs and/or fragments. The acid insoluble organic fraction of a sub-sample was submitted for AMS dating without separation of the humic/humin fractions; no stepped combustion process was carried out. Five radiocarbon dates were obtained from gastropod shells. Four individual shells were dated by Beta Analytic Inc.; pre-treatment involved removal of the surface through acid etching (BA-344846 $13.4 \mathrm{mg}$; BA-344849 9.7 mg; BA$334484713.0 \mathrm{mg}$; BA-3344848 $11.4 \mathrm{mg}$ ). A small (12.4 mg), weathered gastropod was dated at the Australian National University (S-ANU 37218). The protocol included: (a) removing the surface with a scalpel and leaching the remaining sample in $\mathrm{HCl}$ until $10 \mathrm{wt} \%$ was lost to exclude recrystallized material; (b) powdering the sample and submitting it to x-ray diffraction (XRD) analysis to test for the presence of calcite, which under normal conditions precipitates from solution as calcite and can be distinguished from the aragonite form of carbonate in most gastropods. XRD was undertaken in a Siemens D501 diffractometer at the ANU operating at $40 \mathrm{~mA}$, and $40 \mathrm{kV}$, using $\mathrm{CuK} \alpha$ radiation with a step size and time of $0.5^{\circ} 2 \theta$ and $60 \mathrm{~s}$ between $25-50^{\circ} 2 \theta$ on the Bragg scale, and Siroquant ${ }^{\mathrm{TM}}$ to quantify the calcite 
content; (d) reacting the powdered sample with $85 \% \mathrm{H}_{3} \mathrm{PO}_{4}$ in an evacuated Vacutainer ${ }^{\mathrm{TM}}$, and collecting and purifying the $\mathrm{CO}_{2}$ generated cryogenically before conversion to graphite with hydrogen over an iron catalyst; (e) carrying out AMS dating following procedures specified in Fallon et al. ${ }^{64}$ and subtracting sample preparation backgrounds based on measurements of samples of ${ }^{14} \mathrm{C}$-free $\mathrm{CO}_{2}$. All radiocarbon dates were calibrated using $\mathrm{OxCal}$ v.4.2.4 $4^{65}$, IntCal13 curve ${ }^{66,67}$. Further information on radiocarbon dating in Supplementary Information 6.2.

Optically Stimulated Luminescence (OSL) Dating. An OSL date was obtained at the University of Oxford (X6481) from a block sample of the semi-consolidated sediment that was exposed through the excavation of KNM-WT 71251. Sample preparation for OSL dating involved the removal of the light-exposed outer $2 \mathrm{~cm}$ of the block under filtered laboratory lighting (low intensity LEDs with peak emission at $559 \mathrm{~nm}$ ) and the extraction of sand sized (90-125 $\mu \mathrm{m}$ ) quartz mineral grains (prepared through wet sieving, $\mathrm{HCl}$ acid digestion, etching in HF acid (45\%), and heavy liquid flotation (sodium polytungstate)). Due to the common occurrence of feldspar mineral grains within the mineral matrix, the sample was also subjected to a prolonged (two weeks) etching in H2SiF6. Purified quartz grains were mounted as multi-grain mono-layers of circa $4 \mathrm{~mm}$ diameter onto aluminium discs with a silicone oil adhesive. OSL measurements were conducted using an automated Risø luminescence reader ${ }^{67}$, and are based on a conventional single-aliquot regeneration (SAR) measurement protocol ${ }^{68,69}$. In order to minimize the contribution of residual feldspathic components to the quartz signal, each OSL measurement was preceded by an infrared bleach $^{70,71}$. Optical stimulation for single aliquots was provided by clusters of blue light emitting diodes (42 Nichia $470 \Delta 20 \mathrm{~nm}$ ) providing a sample stimulation power of $\sim 32-36$ $\mathrm{mWcm}^{-2}$. The natural and regenerative doses were preheated to $240{ }^{\circ} \mathrm{C}$ for 10 seconds (s), and the fixed test doses used to correct for sensitivity changes were preheated to a reduced 
temperature of $220{ }^{\circ} \mathrm{C}$, before optical stimulation. The choice of preheat combination followed a series of dose recovery experiments conducted at $210{ }^{\circ} \mathrm{C}, 230{ }^{\circ} \mathrm{C}, 240{ }^{\circ} \mathrm{C}$ and 250 ${ }^{\circ} \mathrm{C}$. These showed no dependency on temperature, returning dose equivalent (De) values close to unity $(0.97,1.03,0.96$ and 1.04). The presence of infrared-sensitive minerals (e.g. feldspars) was checked using an infrared bleach provided by a solid state laser diode $(830 \Delta 10$ $\mathrm{nm} ; 1 \mathrm{Wcm}^{2}$ ) at $50^{\circ} \mathrm{C}$ for $50 \mathrm{~s}$ before blue light stimulation. The ultraviolet quartz OSL emission at $\sim 370 \mathrm{~nm}$ used for optical dating was detected using an Electron Tubes Ltd 9235QA photomultiplier tube fitted with a blue-green sensitive bialkali photocathode and a 7.5 mm Hoya U-340 glass filter. Laboratory doses used for constructing the dose response curves were provided by a $90 \mathrm{Sr} / 90 \mathrm{Y}$ ceramic beta source housed within the reader and calibrated against a gamma irradiated Risø National Laboratory standard ${ }^{72}$. The standard error on individual De measurements included an instrument reproducibility uncertainty of $1 \%$, as well as a random $1 \%$ uncertainty arising from photon counting statistics. The total uncertainty on the final equivalent dose includes a further systematic component of $4 \%$ (added in quadrature) to account for uncertainties in the calibration of the in-built beta source. The equivalent dose was determined from the first second of the OSL decay curve (Extended Data Fig. 3d) using the final $5 \mathrm{~s}$ as background noise (total stimulation time was 50s). Dose response curves (Extended Data Fig. 3e) were fitted with the Analyst software package ${ }^{73}$ using a double saturating exponential function and the distribution of replicate De measurements is presented in Extended Data Fig. 3f. Given the internal consistency between replicate De measurements and the otherwise favourable OSL characteristics of the multigrain quartz aliquots (Supplementary Information 6.3), a central age model $^{74}$ was used to obtain the final equivalent dose estimate for purposes of age calculation. Dose rate calculations are based on the concentrations of radioactive elements (K, Th and $U)$ within the sample as determined from elemental analysis performed on homogenized and pulverized 
subsamples (approximately $10 \mathrm{~g}$ of sediment) by inductively coupled mass spectrometry (ICPMS) and inductively coupled atomic emission spectroscopy (ICP-AES). No direct evaluation of ${ }^{238} \mathrm{U}$ and ${ }^{232} \mathrm{Th}$ within the quartz grains was made as the internal dose rate only provides a very minor contribution $(<300 \mu \mathrm{Gy} / \mathrm{kyr})$ to the total dose rate ${ }^{75-77}$ and is often considered to be negligible. However, an assumed internal (alpha and beta) dose rate of $0.03 \pm 0.01 \mathrm{~Gy} / \mathrm{kyr}$ based on more recently published ${ }^{238} \mathrm{U}$ and ${ }^{232} \mathrm{Th}$ measurements for etched quartz ${ }^{78,79}$ and an alpha efficiency factor of $0.04 \pm 0.01^{80}$ was included in the dose rate calculations. Owing to technical difficulties in measuring radionuclide concentrations in quartz extracts, a more meticulous and laborious evaluation of the contribution of the internal dose rate was not considered necessary, especially given that that the OSL dating was not aimed at establishing a high resolution chronology. Furthermore, because of the relatively high external dose rate ( $2 \mathrm{~Gy} / \mathrm{kyr}$ ) encountered in this particular environmental setting, there would be little benefit from making a more precise determination. The uncertainty associated with the internal dose rate is not considered to have a significant effect on the reported age estimate. The concentrations of parent isotopes were converted to dose rates according to the updated attenuation factors proposed by Guérin et al. ${ }^{81}$, corrections for grain size ${ }^{76}$, as well as water content $^{82}$. The recorded moisture content from the sample was below one percent. However, this value was not considered to be a good approximation of the mean water content of the sediment throughout the burial period. In order to account for past and seasonal changes in the pore water content, a mean long-term value of $5 \%$ of the dry mass of the sample was used and assigned a relative uncertainty of $60 \%$ for determining the attenuating effect on the dose rate received by the quartz mineral grains. The cosmic-ray dose was calculated according to Prescott and Hutton ${ }^{83}$, taking into account the thickness and density of the overburden as well as the geomagnetic latitude and elevation of the site. Despite the current erosional nature of the landscape, the recorded shallow overburden thickness of $40 \mathrm{~cm}$ is considered to represent 
the best long-term approximation. There is no evidence to suggest that the site was ever covered by nearby dunes, which are believed to have accumulated relatively recently. Observations on the OSL dating of sample X6481 from Nataruk in Supplementary Information 6.3.

Uranium-Series dating. Laser ablation U-series analyses was carried out on 18 skeletal samples following principles and procedures described in Grün et al. ${ }^{84}$. Laser ablation data were obtained from spot analyses collected on the cortical sections of the bone on lines perpendicular to the surface. On thick cortical bones, data were collected along a single line; on samples with thinner cortical bone sections (e.g. ribs with a spongy centre), spots were obtained along several lines. No individual age calculation was carried out when the Uconcentrations were below about $0.5 \mathrm{ppm}$ and detrital ${ }^{232} \mathrm{Th}$ was observed ${ }^{84}$ (elemental U/Th ratios below 100). If there were $>4$ remaining data points, these were used for the calculation of diffusion-adsorption-decay (DAD) age estimates ${ }^{85}$. DAD calculations were only considered successful if there was no conflict between the ${ }^{230} \mathrm{Th} /{ }^{238} \mathrm{U}$ and ${ }^{234} \mathrm{U} /{ }^{238} \mathrm{U}$ data across the bone. In cases where these conditions were not met, the average spot data were used to calculate average ages. Detailed information on the U-series results in Supplementary Information 6.4.

30. Broadbent, B. H. \& Golden, W. H. Bolton Standards of Dentofacial Developmental Growth. (CV Mosby Company, 1975).

31. Smith, B. H. in Advances in Dental Anthropology (Kelley, M. A. \& Larsen, C. S.) 143-168 (Wiley-Liss, 1991).

32. Scheuer, L. \& Black, S. M. Developmental juvenile osteology. (San Diego, CA: Academic Press, 2000).

33. Bass, W. M. Human osteology: a laboratory and field manual. (Missouri Archaeological Society, 1995).

34. Buikstra, J. E. \& Ubelaker, D. H. Standards for Data Collection from Human Skeletal Remains. (Arkansas Archaeological Survey Research Series No. 44, 1994).

35. Brooks, S. \& Suchey, J. M. Skeletal age determination based on the os pubis: a comparison of the Acsádi-Nemeskéri and Suchey-Brooks methods. Human Evolution 5, 227-238 (1990).

36. Brothwell, D.R. Digging up bones. (Oxford: OUP, 1981). 
37. İşcan, M. Y., Loth, S. R. \& Wright, R. K. Metamorphosis at the sternal rib end: a new method to estimate age at death in white males. American Journal of Physical Anthropology 65, 147-156 (1984).

38. İşcan, M. Y., Loth, S. R. \& Wright, R. K. Age estimation from the rib by phase analysis: white females. Journal of Forensic Sciences 30, 853-863 (1985).

39. Brink, O., Vesterby, A. \& Jensen, J. Pattern of injuries due to interpersonal violence. Injury 29, 705-709 (1998).

40. Jurmain, R. et al. Paleoepidemiological patterns of interpersonal aggression in a prehistoric central California population from CA-ALA-329. American Journal of Physical Anthropology 139, 462-473 (2009).

41. Kjaerulff, H., Jacobsen, J. \& Aalund, O. Injuries due to deliberate violence in areas of Denmark. III. Lesions. Forensic Sci 41, 169-180 (1989).

42. Martin, D. L. \& Frayer, T. Troubled times: osteological and anthropological evidence of violence. (Gordon and Breach, 1997).

43. Shepherd, J. P., Shapland, M., Pearce, N. X. \& Scully, C. Pattern, severity and aetiology of injuries in victims of assault. Journal of the Royal Society of Medicine 83, 75-78 (1990).

44. Quatrehomme, G. \& İşcan, M. Y. Postmortem skeletal lesions. Forensic Science International 89, 155-165 (1997).

45. Angel, J. L. Patterns of fracture from Neolithic to modern times. Anthropology of Kozlemenyek 18, 9-18 (1974).

46. Brickley, M. \& Smith, M. Culturally determined patterns of violence: biological anthropological investigations at a historic urban cemetery. American Anthropologist 108, 163-177 (2006).

47. Fibiger, L., Ahlström, T., Bennike, P. \& Schulting, R. J. Patterns of violence-related skull trauma in neolithic southern scandinavia. American Journal of Physical Anthropology 150, 190-202 (2012).

48. Levin, L. et al. Incidence and severity of maxillofacial injuries during the Second Lebanon War among Israeli soldiers and civilians. J. Oral Maxillofac. Surg. 66, 1630-1633 (2008).

49. Steadman, D. W. Warfare related trauma at Orendorf, a middle Mississippian site in west-central Illinois. American Journal of Physical Anthropology 136, 51-64 (2008).

50. Owsley, D. W., Berryman, H. E. \& Bass, W. M. Demographic and osteological evidence for warfare at the Larson site, South Dakota. Plains Anthropological Memoirs 13, 119-131 (1977).

51. Walker, P. L. in Troubled times: violence and warfare in the past (Martin, D. \& Frayer, D. W.) 145-180 (Gordon and Breach, 1997).

52. Berryman, H. E. \& Haun, S. J. Applying forensic techniques to interpret cranial fracture patterns in an archaeological specimen. International Journal of Osteoarchaeology 6, 2-9 (1996).

53. Berryman, H. E. \& Symes, S. A. in Forensic Osteology (Reichs, K. J.) 333-352 (Charles C Thomas Publisher, 1998).

54. Galloway, A. in Broken bones: anthropological analysis of blunt force trauma (Galloway, A.) 81-112 (Charles C Thomas Publisher, 1999).

55. Kimmerle, E. H. \& Baraybar, J. P. Skeletal trauma: identification of injuries resulting from human rights abuse and armed conflict. (Taylor \& Francis, 2008).

56. Knüsel, C. J. in Warfare, violence and slavery in prehistory (Parker Pearson, M. \& Thorpe, I. J. N.) 49-65 (Archaeopress, 2005).

57. Lovell, N. C. Trauma analysis in paleopathology. American Journal of Physical Anthropology 104, 139-170 (1997). 
58. Ortner, D. in Skeletal trauma: identification of injuries resulting from human rights abuse and armed conflict (Kimmerle, E. H. \& Baraybar, J. P.) 21-86 (CRC Press, 2008).

59. Passalacqua, N. V. \& Fenton, T. W. in A companion to forensic anthropology (Dirkmat, D. C.) 400-411 (Blackwell, 2012).

60. Roberts, C. in Human Paleopathology: current synthesis and future options (Ortner, D. \& Aufderheide, A. C.) 225-240 (Smithsonian Institution Press, 1991).

61. Rodríguez-Martín, C. in Forensic Anthropology and Medicine (Schmitt, A. et al.) 197-221 (Humana Press, 2006).

62. Wheatley, B. Perimortem or post-mortem bone fractures? An experimental study of fracture patterns in deer femora. Journal of Forensic Science 53, 69-72 (2008).

63. Letourneux, C. \& Petillon, J. Hunting lesions caused by osseous projectile points: experimental results and archaeological implications. Journal of Archaeological Science 35, 2849-2862 (2008).

64. Fallon, S. J., Fifield, L. K. \& Chappell, J. M. The next chapter in radiocarbon dating at the Australian National University: Status report on the single stage AMS. Nuclear Instruments and Methods in Physics Research Section B 268, 898-901 (2010).

65. Bronk Ramsey, C., Scott, E. M. \& van der Plicht, J. Calibration for archaeological and environmental terrestrial samples in the time range $26-50 \mathrm{ka}$ cal BP. Radiocarbon 55, 2021-2027 (2013).

66. Reimer, P. et al. IntCal13 and Marine13 Radiocarbon Age Calibration Curves 050,000 Years cal BP. Radiocarbon 55, 1869-1887 (2013).

67. BØtter-Jensen, L. Luminescence techniques: instrumentation and methods. Radiation Measurements 27, 749-768 (1997).

68. Murray, A. S. \& Wintle, A. G. Luminescence dating of quartz using an improved single-aliquot regenerative-dose protocol. Radiation Measurements 32, 57-73 (2000).

69. Wintle, A. G. \& Murray, A. S. A review of quartz optically stimulated luminescence characteristics and their relevance in single-aliquot regeneration dating protocols. Radiation Measurements 41, 369-391 (2006).

70. Banerjee, D., Murray, A. S., Bøtter-Jensen, L. \& Lang, A. Equivalent dose estimation using a single aliquot of polymineral fine grains. Radiation Measurements 33, 73-94 (2001).

71. Wallinga, J., Murray, A. S. \& Bøtter-Jensen, L. Measurement of the dose in quartz in the presence of feldspar contamination. Radiat Prot Dosimetry 101, 367-370 (2002).

72. Hansen, V., Murray, A. S., Buylaert, J. P., Yeo, E. Y. \& Thomsen, K. J. A new irradiated quartz for beta source calibation. Radiation Measurements (2015). at $<\mathrm{http}: / / \mathrm{dx} / \mathrm{doi} / \mathrm{org} / 10 / 1016 / \mathrm{j} / \mathrm{radmeas} .2015 .02 .017>$

73. Duller, G. A. T. The Analyst software package for luminescence data: overview and recent improvements. Ancient TL 33, 35-42 (2015).

74. Galbraith, R. F., Roberts, R. G., Laslett, G. M., Yoshida, H. \& Olley, J. M. Optical dating of single and multiple grains of quartz from Jinmium Rock Shelter, northern Australia: Part I, Experimental design and statistical methods. Archaeometry 41, 339-364 (1999).

75. Sutton, S. R. \& Zimmermann, D. W. Thermoluminescence dating: radioactivity in quartz. Archaeometry 20, 67-69 (1987).

76. Mejdahl, V. Thermoluminescence dating: Beta-dose attenuation in quartz grains. Archaeometry 21, 61-72 (1979).

77. Grün, R. \& Fenton, C. Internal dose rates of quartz grains separated from fault gouge. Ancient TL 29, 26-28 (1990). 
78. De Corte, F., Vandenberghe, D., Buylaert, J. P., Van den Haute, P. \& Kucera, J. Relative and $\mathrm{k} 0$-standardized INAA to assess the internal (Th, $\mathrm{U}$ ) radiation dose rate in the 'quartz coarse-grain protocol' for OSL dating of sediments: Unexpected observations. Nuclear Instruments and Methods in Physics Research (A) 564, 743 751 (2006).

79. Vandenberghe, D., De Corte, F., Buylaert, J. P., Kucera, J. \& Van den Haute, P. On the internal radioactivity in quartz. Radiation Measurements 43, 771-775 (2008).

80. Rees Jones, J. \& Tite, M. S. Optical dating results for British archaeological sediments. Archaeometry 39, 177-178 (1997).

81. Guerin, G., Mercier, N. \& Adamiec, G. Dose-rate conversion factors: update. Ancient TL 29, 5-8 (2011).

82. Zimmermann, D. W. Thermoluminescent dating using fine grains from pottery. Archaeometry 13, 29-52 (1971).

83. Prescott, J. R. \& Hutton, J. T. Cosmic ray contributions to dose rates for luminescence and ESR dating: Large depths and long-term time variations. Radiation Measurements 23, 497-500 (1994).

84. Grün, R., Eggins, S., Kinsley, L., Mosely, H. \& Sambridge, M. Laser ablation Useries analysis of fossil bones and teeth. Palaeogeography, Palaeoclimatology, Palaeoecology 416, 150-167 (2014).

85. Sambridge, M., Grün, R. \& Eggins, S. U-series dating of bone in an open system: the diffusion-adsorption-decay model. Quaternary Geochronology 9, 42-53 (2012).

86. Dietze, M. et al. The abanico plot: visualizing chronometric data with individual standard errors. Quaternary Geochronology (2015). at $<$ http://dx.doi.org/10.1016/j.quageo.2015.09.003>

87. Kreutzer, S. et al. Introducing an $\mathrm{R}$ package for luminescence dating analysis. Ancient TL 30, 1-8 (2012).

88. R Development Core Team R: A Language and Environment for Statistical Computing. at $<$ http://CRAN.R-project.org $>$ 
Extended Data Table 1 - Dates of sediments, shells and human remains from Nataruk. Radiocarbon dates have been calibrated against IntCal13 ${ }^{66}$ in OxCal v4.2.4 ${ }^{65}$. Radiocarbon age estimates presented as radiocarbon years before the present (yrs BP) and as calibrated ages (cal BP) with 95\% confidence intervals. OSL and U-series age estimates presented in years (yrs). Error on the OSL age is at $1 \sigma$; errors on the U-series ages are at $2 \sigma$.

\section{Extended Data Table 2 - Chronological synthesis and U-series sample characterisation.}

Extended Data Figure 1 - Location of Nataruk and distribution of finds within the site.

a. Geographical relation of the site of Nataruk to other similarly dated sites in the area and to the reconstructed palaeo-shorelines of Lake Turkana at different extents during the early Holocene maximum transgression (440 m asl, $430 \mathrm{~m}$ asl, $420 \mathrm{~m}$ asl), based on SRTM $90 \mathrm{~m}$ DEM (v 4.1)(source: CGIAR-CSI, http://srtm.csi.cgiar.org); background image: hillshade based on SRTM 90m DEM (v4.1) (Source: CGIAR-CSI, http://srtm.csi.cgiar.org). b. Distribution of finds (human, animal and archaeological remains) at Nataruk; background image: ArcGIS Online Basemap - World Imagery (version 2 October, 2014) (Source: Esri, DigitalGlobe, GeoEye, i-cubed, USDA, USGS, AEX, Getmapping, Aerogrid, IGN, IGP, swisstopo, and the GIS User Community).

Extended Data Figure 2 - The site of Nataruk. a.b. View of the Nataruk site with exposed cranium of KNM-WT 71264 as was first found. c. KNM-WT 71264 after excavation. d. Geomorphological setting of the site of Nataruk, showing pattern of drainage and the small geological fault to the east; background image: ArcGIS Online Basemap - World Imagery (version 2 October, 2014) (Source: Esri, DigitalGlobe, GeoEye, i-cubed, USDA, USGS, AEX, Getmapping, Aerogrid, IGN, IGP, swisstopo, and the GIS User Community). e. 
Elevation profile of the site of Nataruk showing the position of the ridge and NE mounds. $\mathbf{f}$. view of the lagoon carbonate nodules and shells; g. example of human remains in the context of the lagoon sediments, illustrated by the left foot of KNM-WT 71255. Photographs by M.M.L.

\section{Extended Data Figure 3 - Dating of the site of Nataruk and graphic synthesis of OSL}

methodology employed. a. Modelled date (BP) for the sediments above skeletons KNM-WT 71251 and 71260, and the shells associated with skeletons KNM-WT 71251, 71254, 71258, 71264,71274 showing the age and probability distributions. Sample source and association to human remains to the left of individual plots, with the two younger sediment samples from the surface above skeletons at the top, and the shell samples in direct association with human remains below; b. Distribution of estimated U-series ages x U (ppm) for samples 3487 and 3513 (both from skeleton KNM-WT 71264) and 3514 (KNM-WT 71265); c. Average apparent U-series age (1- $\sigma$ standard deviation) and ${ }^{234} U /{ }^{238} U$ ratios of all samples analysed $(\mathrm{n}=17)$ (further information on Extended Data Table 3 and Supplementary Table 8). d. Example of a natural OSL decay curve featuring the integrated signal (in red) and the background counts (in green) obtained from a multigrain quartz aliquot; e. Example of a sensitivity corrected dose response curve for the natural (in red) and regenerative-dose signals using a double exponential fitting procedure; f. Abanico plot featuring the distribution of multigrain quartz De measurements and their associated data precision and error scatter ${ }^{86}$. The plot combines a radial plot (bivariate plot on the left side) with a histogram and kernel density estimate curve (univariate plots on the right side) using the default function tool developed within the package 'Luminescence ${ }^{87}$ for the statistical programming language ' $\mathrm{R}$ '88. The two sigma dispersion range is shown in grey and the red polygon characterizes the one sigma frequency distribution of the primary data. 
Extended Data Figure 4 - Traumatic lesions on skeletons KNM-WT 71251 (a) and KNM-WT 71253 (b). Displayed lesions on KNM-WT 71251 include an embedded projectile on the left parietal bone, a perforating lesion on the right parietal bone, and possible depressed fractures on the left and right knees. Displayed lesions on KNM-WT 71253 include radiating fractures on the frontal bone, and perforating lesions on the $3^{\text {rd }}(?)$ and $7^{\text {th }}$ cervical vertebrae. Red boxes indicate enlarged images of particular lesions; red arrows point to the lesions described in Supplementary Information 3.3.1 and 3.3.2; red dotted line in KNM-WT 71251 delineates the depressed region on the anterior aspect of the left proximal tibia. Photographs by M.M.L.

Extended Data Figure 5 - Traumatic lesions on skeletons KNM-WT 71254 (a) and KNM-WT 71256 (c), and foetal remains found within the body cavity of KNM-WT 71255 (b). Displayed lesions on KNM-WT 71254 include a perforating lesion on the frontal bone, and linear perforations on the mandible and the right trapezoid. Displayed lesions on KNM-WT 71256 include perforating lesions on cervical and thoracic vertebrae, and fractures on the $2^{\text {nd }}$ and $3^{\text {rd }}$ right metacarpals. Metacarpal images show four views of the element to illustrate the extent of the fractures; inset of $2^{\text {nd }}$ metacarpal shows palmar view of lesion, insets of $3^{\text {rd }}$ metacarpal show palmar (a) and dorsal-lateral (b) fractures. Red boxes indicate enlarged images of particular lesions; red arrows point to the lesions described in Supplementary Information 3.3.3 and 3.3.5. Further information on KNM-WT 71255 and foetal remains in Supplementary Information 3.3.4. Photographs by M.M.L.

Extended Data Figure 6 - Traumatic lesions on skeletons KNM-WT 71257 (a) and KNM-WT 71259 (b). Displayed lesions on KNM-WT 71257 include depressed fractures on the left parietal and multiple radiating fractures across the skull, with the mandible 
unaffected. Displayed lesions on KNM-WT 71259 include three fractures to ribs, including on two consecutive ribs, and possible depressed fractures to the right knee. Red boxes indicate enlarged images of particular lesions in KNM-WT 71259, including the unnatural position of the left foot; red arrows point to the lesions described in Supplementary Information 3.3.6 and 3.3.8; red dotted line in KNM-WT 71259 delineates the depressed region on the anterior aspect of the right distal femur. Photographs by M.M.L.

\section{Extended Data Figure 7 - Traumatic lesions on skeletons KNM-WT 71263 (a), KNM-} WT 71264 (b) and KNM-WT 71265 (c). Displayed lesions on KNM-WT 71263 include a linear perforating lesion, with associated depressed fracture on the frontal bone, and a perforation on the right temporal bone. Displayed lesions on KNM-WT 71264 include depressed fractures on the frontal and left parietal bones, and multiple radiating fractures across the skull, as well as a healed (?) perforating lesion on the frontal bone. Displayed lesions on KNM-WT 71265 include a depressed fracture on the frontal bone. Red boxes indicate enlarged images of particular lesions; red arrows point to the lesions described in Supplementary Information 3.3.10, 3.3.11 and 3.3.12; red dotted line in KNM-WT 71265 delineates what would have been the natural profile of the bone. Photographs by M.M.L. 
Sample of sediments above KNM-WT 71251 and

(7) KNM-WT 71260 , and from the deflated surface around KNM-WT 71274

Shell samples prised from skeletons (KNM-WT 71258

\& WT 71264), from the excavation of KNM-WT 71254 ,

from the deflated surface around KNM-WT 71274, and from the OSL sample (KNM-WT 71251)

- OSL sample from edge of KNM-WT 71251 excavation 

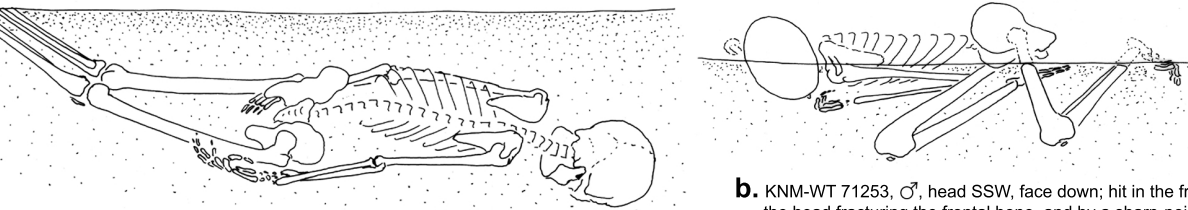

a. KNM-WT 71251, $\mathrm{O}^{7}$, head ESE, face down; hit by at least two projectiles to the head, one embedded in the cranium, and with a blunt instrument on the knees, falling face down into the lagoon

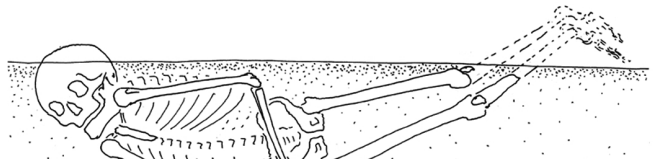

C. KNM-WT 71254 , O?? head S, face E; hit in the forehead, received a sharp-impact to the right cheek that cut into the mandible, and sustained a fracture on the palmar side of the right hand, possibly while parrying a blow, or breaking a fall

b. KNM-WT 71253, O', head SSW, face down; hit in the front of the head fracturing the frontal bone, and by a sharp-pointed weapon on the lower neck
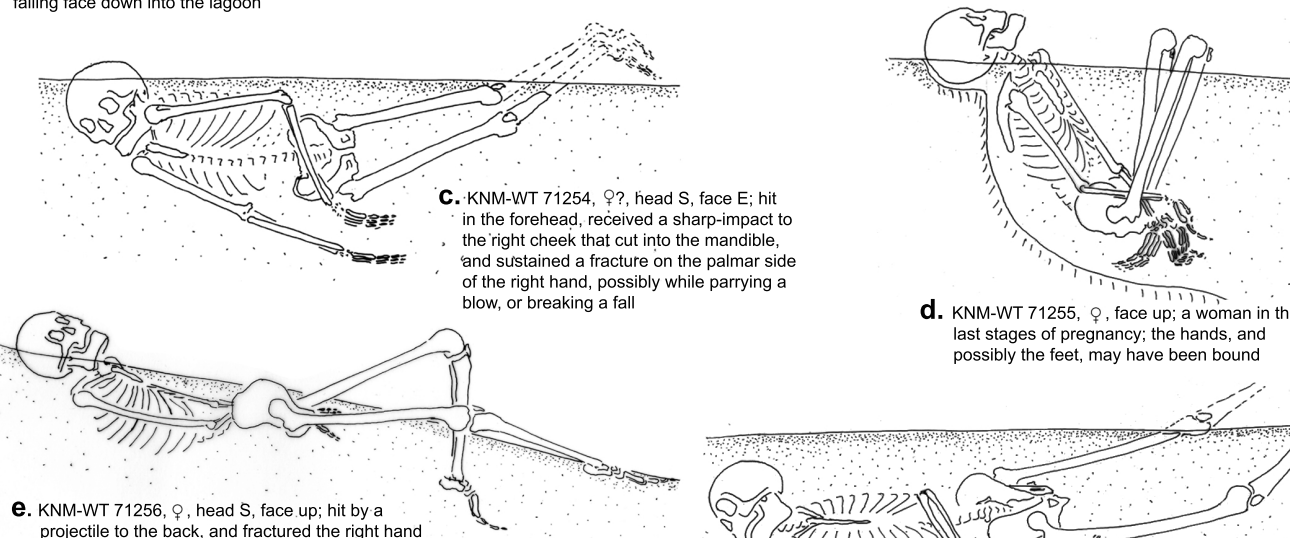

d. KNM-WT 71255 , 0 , face up; a woman in the last stages of pregnancy; the hands, and possibly the feet, may have been bound projectile to the back, and fractured the right hand

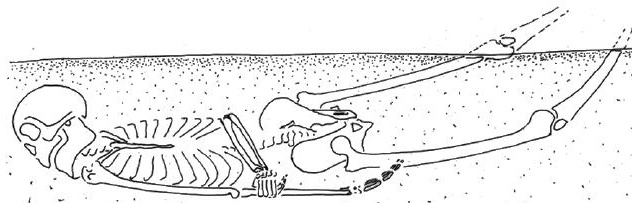

f. KNM-WT 71257, $\sigma^{7}$, head N, face W/down; hit in the head with a blunt instrument, and fell into the lagoon probably with a broken neck

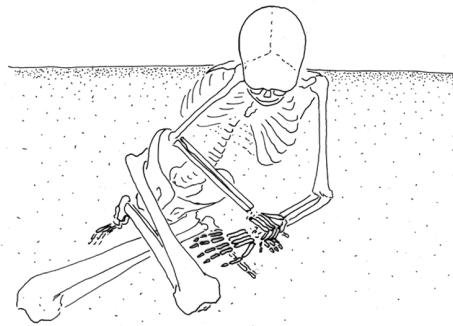

h. KNM-WT 71259, $Q$, head S, face down, chin on thorax; this woman received one or more blunt-force blows to her thorax and knees, which were fractured; the left foot was unnaturally bent, suggesting it may also have been broken; her hands may have been bound

i. KNM-WT 71260, $\sigma^{7}$, head S, face W; no evidence of trauma but hands may have been bound

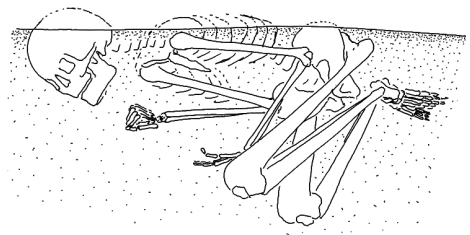

j. KNM-WT 71263, $\sigma^{7}$, head NE, face W/down; received a blow to the face that either cut or fractured the underlying bone, and was possibly hit by a projectile in the right side of the head
I. KNM-WT 71265 , o, head N, face W: hit in the front of the head with a blunt instrument that fractured and depressed the frontal bone (skeleton too poorly preserved for reconstruction). 
b.

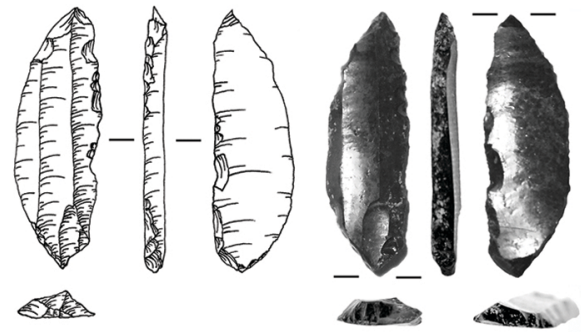

a.

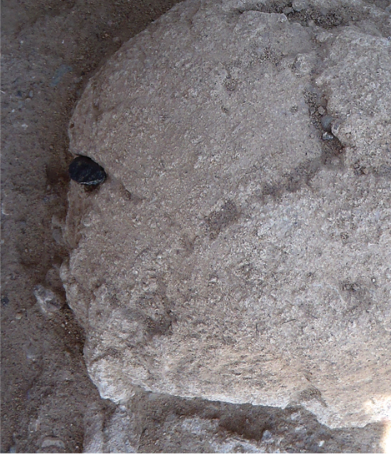

d.

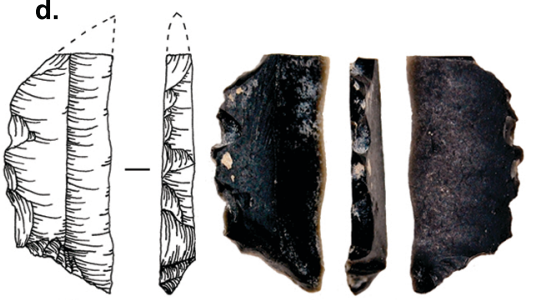

c.

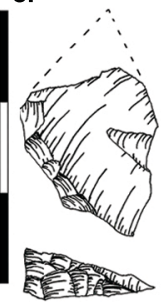

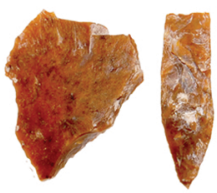

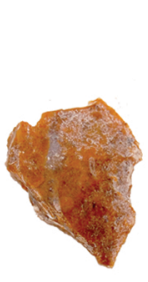

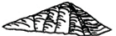

